\title{
Computers and Computing in Society
}

Valérie Schafer

Frank Bösch (Ed.) 2018. Wege in die Gesellschaft. Computernutzung in der Bundesrepublik (1955-1990). Geschichte der Gegenwart, Bd. 20. Göttingen: Wallstein, geb., 326 S., $€ 29.90$, ISBN: 978-3-83533-290-4.

Marie Hicks 2017. Programmed Inequality. How Britain Discarded Women Technologists and Lost Its Edge in Computing. Cambridge, MA: MIT Press, brosch., 352 S., US-\$ 20.00, ISBN: 978-026253-518-2.

Joy Lisi Rankin 2018. A People's History of Computing in the United States. Cambridge, MA: Harvard University Press, geb., $336 \mathrm{~S}$., US-\$29.95/€ 27.00, ISBN: 978-0-67497-097-7.

One way that we could make our subject more engaging and relevant to others is to focus on people rather than machines. One of the most significant insights of recent scholarship in the history of technology has been the realization that technological change is as much driven by social processes as by inherent technological imperatives. (Ensmenger 2004: 96)

Several new approaches have been developed in the domain of computing and digital technologies history over a period of less than fifteen years. The historiography initially reflected a fascination with the machines themselves, as recounted by those involved at first hand. For example Herman Goldstine, one of the ENIAC contributors in the latter half of the World War II, wrote The Computer from Pascal to von Neumann (Goldstine 1972), a book that illustrates these internalist approaches. Michael Mahoney noted in The History of Computing in the History of Technology 
that historians first focused on the prehistory and early development of computers, on key figures and on the most well-known technologies, and were slow in understanding the challenges that other histories of technology had already addressed. He concluded that "this literature represents for the most part an 'insider' history, full of facts and firsts" (Mahoney 1988: 114). He advocated a focus on information technology both as a system and as a component of a wide variety of different and interdependent systems.

However, the initial focus on machines gave way to a broader historical examination of Information Age's various roots. The books Computer: A History of the Information Machine (Campbell-Kelly \& Aspray 1996), A History of Modern Computing (Ceruzzi 1998) and A Nation Transformed by Information (Chandler \& Cortada 2003) are just a few examples of this new path taken towards a more social assessment of computing history.

In 2007 Thomas Misa proposed an even more radical shift from an object-centred study to one focussed on a set of activities and processes that are social, economic and political as well as technical in his paper "Understanding 'How Computing Has Changed the World"' (Misa 2007). His proposal fully integrated the challenges of globalisation and controversy, which were then examined further in Paul Edwards' study A Vast Machine: Computer Models, Climate Data, and the Politics of Global Warming (Edwards 2010). The widespread use of Information and Communications Technology (ICT) not only in the professional world but also by the general public through the use of personal computers and data networks in daily life, has encouraged historians to place greater emphasis on societal issues that were already prominent in other disciplines, such as the sociology of innovation.

This review essay aims to highlight some of these recent trends within the history of computing and information technology through the consideration of three recently published books (Hicks 2017; Rankin 2018; Bösch 2018). They are increasingly opening up to approaches that are oriented towards society and actors, whether the latter are producers, regulators, users, or even maintainers (Russell \& Vinsel 2016). This is achieved with historical rigour by the authors, who highlight the history of a field that is not only scientific, technical, industrial and economic, but also profoundly social, and which is marked by multiple debates, negotiations and power relationships. 


\section{Several Paths, Temporalities, Spaces and Sources}

Although all three books discussed in this review offer a social history of computing and computers, they differ in their chronological and thematic framework as well as in their periodization. They do nevertheless all break away from chronologies based on machines and the "ages of IT", preferring to include institutional, political and legislative aspects. Countering the mainstream, popular narrative, which "jumps from the oppression of 1960s mainframes to the liberation of personal computers in 1975-1985 to the glorious unification and diversification of the 1990s Internet", Rankin emphasises "that personal and social networked computing thrived before personal computers” (Rankin 2018: 229).

Marie Hicks' Programmed Inequality. How Britain Discarded Women Technologists and Lost its Edge in Computing focuses on Great Britain, with a strong emphasis on the labour force. The study begins in the 1930s and ends in the late 1970s, a chronology chosen by Hicks to cover the period from when women entered computing through code breaking and data processing during a time of "gendered war work" to the progressive decline of female presence in this field. It is organized into five chronological chapters that show that Britain's computer "revolution" did not create a gendered "revolution", and it illustrates how "the British case offers a powerful example of how cutting-edge technologies often run counter to social progress and economic justice" (Hicks 2017: 4-5). The study deliberately focuses on the labour force rather than examining British computer manufacturers from a top-down or internal perspective. The wide variety of sources used for this study are presented on pages 295-309 and show that Hicks has accessed extensive documentation from a number of primary sources, including programming manuals, inhouse magazines, trade union-related records (e.g. those published by the Women's Trade Union Congress), internal government documents, ICL archives, employment records, brochures and ephemera from several major British computer companies, oral interviews, industry reports, literature management, advertising and finally computing manuals. This enables her to demonstrate how "technologies often cement or widen existing social and economic divisions rather than break them down" (Hicks 2017: 224). While the sources supporting Hicks' highly documented book remain "traditional" - although the book nevertheless reflects a remarkable effort to assemble a wide range of varied materials from institutions, states and companies-, its original perspective and analytical strength provides another vision of the computerization of Great Britain, with detailed analyses of representations and in particular advertising photos such as the photograph illustrating on the book cover, which shows Cathy Gillespie 
performing the initial program load of the CEGB's new IBM 360 and is analysed on pages 140-142. Hicks' book has been critically acclaimed since its publication, and has won the PROSE Award for History of Science, Technology, and Medicine from the Association of American Publishers, the Sally Hacker Prize from the Society for the History of Technology, the Stansky Prize from the North American Conference on British Studies and the Wadsworth Prize from the British Business Archives Council.

Frank Bösch's book is an edited volume spanning the period from 1955 to 1990. Though focussing in particular on West Germany, developments in the East Germany are also examined, notably in Martin Schmitt's chapter on the computerization of banking in the Credit Economy of West and East Germany (Schmitt in Bösch 2018: 126-146). The volume is organized into three main parts: Security and Control, Digital Work Environments and Alternative Uses. Preceded by Bösch's precise and instructive guide into digital society, these three topics are covered in twelve chapters, which are the result of numerous discussions between the authors at the Centre for Contemporary Historical Research in Potsdam.

Finally, Joy Lisi Rankin's research begins with US computing history in the 1960s and 1970s at Dartmouth College in New Hampshire, analysing the abundant, creative and diverse nature of the research, networks and uses that were being developed around time-sharing and an increasingly interactive computer field. In this context, Rankin describes the emergence and development of innovations such as the BASIC language, EDUCOM (an inter-university communications council created by academic leaders across the United States in 1965 to share resources in computing and communications technology), and PLATO, an early computing network developed at the University of Illinois that had 950 connected terminals in 1975, which allowed the use of new forms of computer-mediated communication through Bulletin Board Systems (BBS), emails, and so on.

Despite focussing on three different locations, all three books look beyond their featured areas. For instance in Bösch's book, Constantin Goschler, Christopher Kirchberg and Jens Wegener analyse security, democracy and the transparency of electronic data network systems in West Germany and in the United States in the 1970s and 1980s. They seek to understand how tensions between "Security, Democracy and Transparency" developed in the context of the expansion of computer-based data network systems of West German and North American security services. Kim Christian Priemel, in turn, compares in his chapter "Multiple Innovation" the impact of computers on the labour relations in industrial printing in West Germany, the United States and Great Britain between 1962 and 1995. 
All three books offer relevant changes of scale, whether they explore the Central Computer Bureau as "A microcosm of the State's Computing" (Hicks 2017: 160-167), enter the small university world of Dartmouth with Rankin or follow the digitization in municipal utilities as does Paul Erker in Bösch's volume, who analyses the Munich public utility company. Together, these individual and sometimes micro-stories add more depth to the global history of computing, as the authors are careful to articulate their subject within the framework of broader history and research. Thus Rankin, for example, draws comparisons between the networks she studies and the development of ARPANET (Paloque-Bergès \& Schafer 2019) at the end of the 1960s, highlighting their connection and relationships.

These three dense and extremely well-documented books lead us to think about turning points occurring at different periods in time, either in terms of technology-despite major trends such as miniaturization-or in terms of political and industrial developments and decisions made according to the countries or sectors studied. All three works emphasise the non-linearity of computing history and even the paradoxes inherent to its turning points. One example is the description of the 1960 s and 1970s, a period that is related with a counter-cultural turn, as described, for instance, by Julia Gül Erdogan in her chapter (in Bösch's volume) about hacker culture in Germany. This period is not synonymous of liberating change in Hicks' study of Great Britain. She notes a rise in technocratism from the mid-1960s onwards (Chapter 4 is entitled "The Rise of the Technocrat: How State Attempts to Centralize Power through Computing Went Astray, 1965-1969"). Bösch's book also identifies this problem at the outset of a computer-monitored society. The rise of technocratism and the transition of individuals from users to consumers are palpable in each book, or in Rankin's words: “I contend that each of the computing communities described in previous chapters struggled with the transition from computing citizenship to computing consumption" (Rankin 2018: 9-10). She demonstrates how PLATO's plasma screens attracted the Control Data Corporation, how the free BASIC programs fuelled the imagination of Steve Wozniak and Bill Gates and how the Minnesota software library was a complement for the hardware of Apple Computers.

\section{Entwining Technology and Society}

The three books cover a wide range of the computing history across the different periods of its development, from the pre-war machines described in Hicks' book, the development of time-sharing considered in Rankin's 
research on the IBM 650, whose series production began in West Germany in 1956, as noted in Bösch's book. These works not only consider activities such as data processing, operating, programming, networking, gaming and sharing, but also examine the multiple evolutions of the functions of computers and of the relationship between users and computers, from mainframes to smaller computers (and to the personal computing of alternative communities in Bösch's book).

This is the point to briefly mention a fourth book: Wie die Welt in den Computer kam. Zur Entstehung digitaler Wirklichkeit (How the World Entered the Computer. The Emergence of Digital Reality, Gugerli 2018), also published in 2018. This 250-page book by David Gugerli, Professor for the History of Technology at ETH Zürich, seems to have a similar topic as the three works featured here, yet it does not provide a real social approach to computers. Its five chapters are based on information functions, from calculating, programming and formatting to connecting, delimiting and saving. It is rather a general, well-documented approach for an audience wishing to learn about the main stages of computerization. The proposed narrative on the history of computing is much more traditional and is mainly centred on the United States, with some references to other rich Western countries when Gugerli addresses, for example, the German case or the policy of standardization of OSI for open networks and X25 for packet-switching protocols. This last example demonstrates clear explanations but makes limited use of recent historiography, omitting references to works such as Andrew Russell's excellent book on the topic: Open Standards and the Digital Age (2014). However, it is difficult to provide an exhaustive analysis in a rapidly developing and vast research field, and Gugerli's clear narrative undeniably provides useful reference points and a reliable introduction to the domain.

The three books discussed here have a more ground-breaking historiographical approach, and their narrower scope-as noted by Rankin: "I have written this book not to be exhaustive, but to be definitive" (2018: 242) -allows their authors to provide a narrative that is deeply rooted in archives. They can therefore paint a detailed, contextualized picture of the conditions of data shaping, functioning and appropriation, as well as the use of machines. This is notably the case in Hicks' study, where she covers the period since data processing began, as well as in Rankin's study of the issues related to time sharing and networking. The latter also includes some rather exciting passages on computer games (the Dartmouth project encouraged game creation and game playing) as well as on the birth and development of BASIC, a successful programming language (Rankin 2018: 69). Bösch's book also provides a very well documented overview of the changing connections between computing, computers and society. 
It presents a number of case studies that provides readers with a new perspective on traditional topics such as administration, security, counterculture and traceability. It allows to develop a comprehensive picture of the computerization process from mainframes to personal computers, that took place in several administrative and professional fields and communities. It also sheds light on the relations that West Germany had with East Germany, as well as with the US and the European computer industry.

Hicks devotes several interesting pages to International Computers and Tabulators (ICT) and International Computers Limited (ICL), the new British company when created in 1968 from a merger to "ensure the government could provision the specific kind of powerful, centralized mainframes it desired and have more influence over the design and production process" (Hicks 2017: 181-182). She delivers fascinating insights into the history of computing, whether for public or private research, academic or more managerial uses, or military or civilian applications. Hicks fully echoes Nathan Ensmenger's comments in "Making Programming Masculine":

The focus of most of this literature has been, understandably enough, on what Judy Wacjman, among others, has called the "hidden history" of women in technology [...]. The goal was to explore what the history of women in computing had to say about women-about their contributions, experiences and abilities. This essay will address instead the flip side of this question: namely, what has the history of women in computing had to say about computing. (Ensmenger in Misa 2010: 121, emphasis in the original)

Likewise Hicks takes up the double challenge of showing not only what the history of women in computing says about women but also what the history of women in computing says about computing.

\section{Gendered Approaches}

Hicks has been a pioneer in this field with her papers, such as "De-Brogramming the History of Computing" (2013) and "Only the Clothes Changed: Women Operators in British Computing and Advertising, 1950-1970" (2010). Other trailblazing publications are Jennifer Light's article on ENIAC Girls "When Computers were Women" (1999), Jane Margolis and Allan Fischer's Unlocking the Clubhouse. Women in Computing (2010), Thomas Misa's edited book Gender Codes. Why Women are Leaving Computing (2010), and Janet Abbate's Recoding Gender. Women's 
Changing Participation in Computing (2012). Light's article sheds light on the role of both, the six female programmers known as the "ENIAC Girls" as well as numerous other women, who worked as human computers during the World War II at the University of Pennsylvania's Moore School on the Electronic Numerical Integrator and Computer, and particularly how these women were made invisible. Subsequent publications extended this early period: Janet Abbate and Tom Misa (with the authors of his edited book) aimed to highlight the spectacular reversal in women's role in computing from the 1980s to the present day-although Janet Abbate's book also provides an extraordinary picture of the careers of women programmers and entrepreneurs, including US-computer programmer and entrepreneur Elsie Shutt and her British counterparts Dina Vaughan and Stephanie Shirley.

In Programmed Inequalities Hicks provides a meticulously detailed insights into the British situation in Great Britain, yet focussing less on such remarkable figures as Vaughan and Shirley, but rather on the "invisible workers". She examines in particular the personal experiences of operators, the programmers' recruitment and training, the bias introduced in management, the developments of the "white-collar labor market", and the effects of the 1970 Equal Pay Act, which came into effect in December 1975. Hicks emphasizes this five-year delay, which allowed employers "to change the organization of work in ways that would make jobs performed by most women incomparable with jobs performed by men. In this way, companies could skirt the legal mandate to raise pay for most of their women employees" (Hicks 2017: 212-213). Ultimately that also brought about the "masculinization" of the profession-with the complicity of the government, as she highlights: "The process of rendering invisible certain categories of workers-and the importance of their work-was critical to the success of early large-scale computing projects aligned with the informational needs of governments" (Hicks 2017: 238). Of the three books considered here, Hicks' book is clearly the one that broaches most explicitly the structural gender discrimination in computing-as already indicated in the title and emphasized in her conclusion that "All History of Computing is Gendered History".

Rankin also takes a gendered approach in her book, devoting several chapters to gender issues with bespoke titles and subheadings such as "Making a Macho Computer Culture", or "How Computing went from Male to Masculine". She also emphasizes intersectionality and "the lack of racial diversity" (in the subsection "Finding Whiteness beyond the Black and White") stating: 
Considering that culture of rough football and racist Native American appropriation, the naming of the student ALGOL compiler (created under the tutelage of Kemeny and Kurtz) with the acronym SCALP in 1962 could be read as the first step in the production of Dartmouth's macho computing culture. (Rankin 2018: 46)

Her book has been met with violent reactions, although it was strongly supported and praised by historians of computing and technologies. It seems important to restate the fact that these gendered approaches clearly go beyond merely a "women's perspective". As Hicks rightly notes, "Fundamentally, this is a history less about women than about how changing constraints of gender, class, and sexuality mould labor forces, industries and nations" (Hicks 2017: 16). On this we might also add, as pointed out by Nathan Ensmenger-whose book The Computer Boys Take Over (2010) offers an excellent analysis of the transition from "Computer Girls" to "Computer Boys" and the masculinization of the profession-, that this history also informs us about computing itself and its development, whether as a scientific or industrial field or as a basis for conceptual visions which were increasingly masculine.

\section{Computing Cultures and Power Dynamics}

All three books show a healthy interest in collectives rather than merely considering individuals (and especially great figures), thus rejecting "the Silicon Valley mythology" that Rankin criticizes in her book: "Let us overwrite the Silicon Valley mythology. Let us look beyond the narrow inspiration of digital Founding Fathers. Let us recover the many people's histories of computing" (Rankin 2018: 242). The decision not to focus merely on some outstanding figures is also echoed by Bösch, who aims to provide new starting points for analyses that distinguish themselves from heroic inventors and pioneer stories (Bösch 2018: 8-9). This vision is explicit in Marie Hicks' book too, this time in the field of women, as the historiography has primarily focused on

uncovering women's contributions and adding them back into the historical record. [...] Understandably, many of these studies focus on women who have a claim to greatness or whose activities put them at the center of major historical events-like Grace Hopper, the ENIAC women, or Dame Stephanie Shirley. (Hicks 2017: 232) 
Whether we consider the labour force in Hicks' study and in the second part of Bösch's Wege in die digitale Gesellschaft, or the history of users in Rankin's book, there is a desire in all three cases to write a more bottom-up history; indeed, A People's History of Computing in the United States adopts a clear "user-up perspective". These choices make it possible to capture new dynamics and in particular to present various digital cultures that developed in universities and computer clubs, in some specific industry sectors such as banking, and in governments. The case study on pension insurance in West Germany developed by Thomas Kasper in Bösch's book clearly addresses how political reforms and computing may be intertwined and shows the complex links, tensions and negotiations between rationality and transparency that were at play in West Germany between 1957 and 1972 in the changing insurance industry.

The three books propose a number of examples to illustrate digital cultures, including the already mentioned hacker culture in Germany, subculture, piracy and the transnational circulation of home computer software as studied by Gleb J. Albert or PLATO's Republic in Rankin's book. The shaping of an early social network as depicted by Rankin, as well as Erdogan's analysis of the development of computer clubs and hacker culture in Germany, provides real insight into computer sociability and autonomous communities. However, the cultural citizenship and culture of sharing that they analyse and the "promises of computing utilities" (the title of Rankin's fourth chapter) are quickly threatened and challenged not only by the rise of technocratism highlighted by Hicks and by several chapters in the book edited by Bösch, and by the redefinitions of the field (Hicks calls one of her sub-sections "Redefining British Computing"), but also by the economic and political stakes that are emerging.

These three books clearly give a positive answer to the old but still relevant question asked in 1980 by Langdon Winner: "Do Artifacts have Politics?" (Winner 1980). Through a journey that transcends the boundaries between the public and private sectors but also shows the interrelationships and negotiations between them, each author sheds light on "The power dynamics behind how technology often heightens existing power differences" (Hicks 2017: 234) and whether this process occurs for commercial, status and professionalization reasons or under the influence of political will. Hicks and Bösch et al. also show the importance and power of the state and the power negotiations throughout their books, demonstrating how the formula "Use Computers For People Not Against Them", which illustrated the back cover of the first issue of the People's Computer Company newsletter in 1972, was particularly relevant at the time and remains applicable today. These three books can be strongly recommended for their resonance with our contemporary period and the associated data 
surveillance, challenges of computing citizenship and sharing, and worsening decline of female presence in computing in recent decades.

\section{References}

Abbate, Janet 2012. Recoding Gender. Women's Changing Participation in Computing. Cambridge, MA: The MIT Press.

Bösch, Frank (ed.) 2018. Wege in die Gesellschaft. Computernutzung in der Bundesrepublik (1955-1990). Göttingen: Wallstein.

Campbell-Kelly, Martin and William Aspray 1996. Computer: A History of the Information Machine. New York: Basic Books.

Ceruzzi, Paul 1998. A History of Modern Computing. Cambridge, MA: The MIT Press.

Chandler, Alfred D. and James Cortada 2003. A Nation Transformed by Information. How Information Has Shaped the United States from Colonial Times to the Present. Oxford: Oxford University Press.

Edwards, Paul 2010. A Vast Machine: Computer Models, Climate Data, and the Politics of Global Warming. Cambridge, MA: The MIT Press.

Ensmenger, Nathan 2004. Power to the People: Toward a Social History of Computing. IEEE Annals of the History of Computing (26): 94-96.

Ensmenger, Nathan 2010. The Computer Boys Take Over. Computers, Programmers, and the Politics of Technical Expertise. Cambridge, MA: The MIT Press.

Goldstine, Herman 1972. The Computer from Pascal to Von Neumann. Princeton: Princeton University Press.

Gugerli, David 2018. Wie die Welt in den Computer kam. Zur Entstehung digitaler Wirklichkeit. Frankfurt am Main: S. Fischer Verlag.

Hicks, Marie 2010. Only the Clothes Changed: Women Operators in British Computing and Advertising, 1950-1970. IEEE Annals of the History of Computing (32): 5-17.

Hicks, Marie 2013. De-Brogramming the History of Computing. IEEE Annals of the History of Computing (35): 88.

Hicks, Marie 2017. Programmed Inequality. How Britain Discarded Women Technologists and Lost its Edge in Computing. Cambridge, MA: The MIT Press.

Light, Jennifer 1999. When Computers were Women. Technology and Culture (40): 455-483.

Mahoney, Michael 1988. The History of Computing in the History of Technology. IEEE Annals of the History of Computing (10): 113-25.

Margolis, Jane and Allan Fischer 2010. Unlocking the Clubhouse. Women in Computing. Cambridge, MA: The MIT Press.

Misa, Thomas 2007. Understanding 'How Computing has Changed the World'. IEEE Annals of the History of Computing (29): 52-63.

Misa, Tom (ed.) 2010. Gender Codes. Why Women are Leaving Computing. Hoboken: WileyIEEE Computer Society Pr.

Paloque-Bergès, Camille and Valérie Schafer 2019. Arpanet (1969-2019), Introduction to a Special Issue. Internet Histories (3): 1-14.

Rankin, Joy Lisi 2018. A People's History of Computing in the United States. Harvard: Harvard University Press.

Russell, Andrew 2014. Open Standards in the Digital Age. Cambridge, MA: Cambridge University Press.

Russell, Andrew and Lee Vinsel 2016. Hail the Maintainers. Aeon. URL: https://aeon.co/ essays/innovation-is-overvalued-maintenance-often-matters-more.

Winner, Langdon 1980. Do Artifacts have Politics? Daedalus (109): 121-36.

Publisher's Note Springer Nature remains neutral with regard to jurisdictional claims in published maps and institutional affiliations. 
Valérie Schafer

Luxembourg Centre for Contemporary and Digital History $(\mathrm{C} 2 \mathrm{DH})$

University of Luxembourg

Belval Campus, Maison des Sciences Humaines, 11, Porte des Sciences 4366 Esch-sur-Alzette

Luxembourg

valerie.schafer@uni.lu 